\title{
Rehabilitation of Lower Extremity Trauma: a Review of Principles and Military Perspective on Future Directions
}

\author{
Benjamin W. Hoyt • Gabriel J. Pavey • Paul F. Pasquina • \\ Benjamin K. Potter
}

Published online: 30 January 2015

(C) Springer International Publishing AG 2015

\begin{abstract}
The rehabilitation of individuals with lower extremity injury is a common but complex problem for the surgical and rehabilitative teams. Basic science tenets of fracture and soft tissue reconstruction and healing guide postoperative weight-bearing and range of motion protocols. In addition to the physiological complications associated with the injury severity, patient outcomes are often influenced by other factors such as patient compliance, pain, depression, and the negative effects of immobility. As a result, novel rehabilitative protocols to include early weight bearing, continuous passive motion, psychosocial intervention, and multimodal pain management are becoming more popular to facilitate rehabilitation
\end{abstract}

This article is part of the Topical Collection on Trauma to the Lower Extremities

B. W. Hoyt • B. K. Potter

Department of Surgery, Uniformed Services University, 4301 Jones

Bridge Road, Bethesda, MD 20814, USA

B. W. Hoyt

e-mail: Benjamin.hoyt@usuhs.edu

G. J. Pavey $•$ B. K. Potter $(\bowtie)$

Department of Orthopaedics, Walter Reed National Military Medical Center, 8901 Wisconsin Ave, America Building (19), 2nd Floor -

Ortho, Bethesda, MD 20889, USA

e-mail: Benjamin.K.Potter.mil@mail.mil

G. J. Pavey

e-mail: Gabriel.j.Pavey.mil@mail.mil

P. F. Pasquina

Department of Physical Medicine \& Rehabilitative, and Center for Rehabilitation Sciences Research, Uniformed Services University of the Health Sciences, 4301 Jones Bridge Road, Bethesda, MD 20814 , USA

e-mail: Paul.F.Pasquina.civ@mail.mil

P. F. Pasquina

Department of Rehabilitation, Walter Reed National Military

Medical Center, 8901 Wisconsin Avenue, Bethesda, MD 20814,

USA and improved patient outcomes. Further supporting the need for this shift in paradigm thinking are outcome studies of both civilian and military trauma patients that demonstrate the negative impact that psychological, social, and economical factors have on outcomes. This report highlights the experience that our team has had in instituting comprehensive rehabilitation strategies to treat injured service members with complex lower extremity trauma from combat.

Keywords Lower extremity trauma $\cdot$ Rehabilitation protocols $\cdot$ Weight bearing $\cdot$ Chronic pain $\cdot$ Limb salvage

\section{Introduction}

Orthopedic trauma of the lower extremity is common in both military and civilian populations. As such, the goal of the surgical and rehabilitative team focuses on the return of a patient to their previous level of function often in the setting of competing short-term goals. For example, aggressive early ambulation, range of motion, and weight bearing may fulfill an expeditious return and mitigate deconditioning but may place fracture fixation or soft tissue repair at risk for failure. Further complicating patient rehabilitation may be poor patient compliance, pain management issues, and immobility. Among the elderly population in particular, immobility can result in serious medical complications such as deconditioning, venous thromboembolic events, catheter-associated infections and pneumonia, and/or decubiti. These poor outcomes have led to some paradigm shifts with some allowances of early weight bearing and range of motion. Furthermore, technical advances in rehabilitative equipment and non-pharmacologic pain modalities have succeeded in promoting more reliable return to function. This article reviews the physiologic rationale for 
long-standing rehabilitation protocols, introduces novel treatment modalities, and offers our experience with implementing novel rehabilitation approaches to combat casualties with complex lower extremity trauma.

\section{Fracture Healing}

Wolff's Law states that the trabeculae in trabecular bone line up with principle stresses placed on the bone during development, thereby allowing bone to adapt to mechanical forces placed on it $[1,2]$. This principle, which has been more broadly applied to include cortical bone, is also relevant to fracture healing. The process of fracture healing is sensitive to strains and requires stability provided by surgical fixation to drive callus formation and neovascularization [3, 4]. However, per Wolff's Law, stress is also critical to this healing process.

Given these facts, the choice of surgical fixation constructs is heavily dependent on fracture characteristics to include location of fracture along the bone, degree of comminution, and soft tissue damage or periosteal disruption. Operative fracture fixation may include internal (i.e., plate and screw) fixation, intramedullary fixation, or external fixation. These various strategies can be manipulated to determine whether a fracture will undergo primary bone healing via endochondral ossification or secondary bone healing following the calcification of cartilage and callus formation.

In addition, fracture fixation can employ a load-bearing or load-sharing construct. With load-bearing constructs such as internal fixation in which the orthopedic device accepts the forces across the fracture site, the patient is typically prevented from full weight bearing to avoid repetitive loading across the device [5] until sufficient healing has been achieved to permit sharing of this stress. In this setting, compression facilitated by the device induces the process of contact healing by osteoclasts and osteoblasts. Conversely, load-sharing constructs such as intramedullary fixation are used for segmental or comminuted fractures and allow for division of interfragmentary strain among fragments. These constructs are more tolerant of early weight bearing as the forces are shared between bone and device, and strain is shared among fragments [6].

Surgeons have historically been hesitant to allow early load bearing after lower extremity fractures to limit risks of loss of reduction and implant failure [7•]. While orthopedic device constructs and physiologic theory support early weight bearing, many providers remain hesitant to this approach. This section will address these concerns, by providing a review of the principles, which are also listed in Table 1, that have generally been accepted as weight-bearing protocols in the rehabilitation of individuals with lower extremity injuries; further, it will introduce more recent outcomes of early weight-bearing protocols.
Internal Fixation

Internal fixation functions to promote primary bone healing through haversian remodeling when bone fragments are intimately fixed and there is absolute stability of the construct. While open reduction, internal fixation (ORIF) provides adequate fixation of most fracture types, interfragmentary instability [5] and excessive axial strain [28] delay fracture healing and may result in malunion, nonunion, or implant failure. Thus, patients are normally non-weight bearing for 6 to 12 weeks following ORIF, particularly for articular fractures.

This approach is supported by much of the existing literature. The plate fixation of calcaneal [8,9], tibial plafond [12], high-grade tibial [16], distal femoral, femoral shaft [29], and acetabular fractures all typically benefit from restricted weight bearing or non-weight bearing for up to 12 weeks after fixation. A notable exception is the use of percutaneous cancellous screw fixation for hip fracture, which may permit immediate weight bearing in the elderly [23-25]. As noted above, compression allows for more rapid weight bearing than indirect reduction, likely explaining the capacity for immediate weight bearing after this type of fixation. There may also be an additional component of elderly patients applying decreased axial force and demonstrating poorer compliance in weight restriction [7•].

\section{Intramedullary Fixation}

Intramedullary (IM) fixation allows for axial loading across the fracture site which promotes callus formation and secondary bone healing. Since IM fixation is more tolerant of repetitive axial loading than plate fixation, its application typically allows earlier ambulation due to the minimal deformation of the system by these forces. Although permitted, not all patients with IM fixation are able to achieve immediate weight bearing because of other complications [19-21]. IM fixation is currently being used with increasing frequency when managing diaphyseal fractures of long bone, including comminuted fractures, without significant increase in complications associated with early weight bearing [18-20, 22]. The increase in popularity with using IM fixation is likely secondary to improved materials, which are currently more rigid and less likely to fail, as well as the positive benefits of allowing early weight bearing as tolerated.

\section{External Fixation}

External fixators can be used to apply compressive, neutral, or distractive forces on bone, allowing treatment of both long bone and periarticular fractures. Due to their low level of tissue disruption and easier removal than internal fixators in 
Table 1 Weight bearing protocols following lower extremity trauma

\begin{tabular}{|c|c|c|}
\hline Injury type & Common fixation methods & Recommendations for initial weight bearing \\
\hline N/A & Amputation & 4-6 weeks pending soft tissue healing and contralateral fractures \\
\hline \multirow[t]{2}{*}{ Calcaneal fracture } & ORIF & NWB for $6-12$ weeks $[8,9]$ \\
\hline & External fixation & Immediate weight bearing as tolerated $[10,11]$ \\
\hline \multirow[t]{2}{*}{ Tibial plafond fracture } & ORIF & NWB for 6-12 weeks [12] \\
\hline & External fixation & Immediate weight bearing as tolerated $[12,13]$ \\
\hline \multirow[t]{2}{*}{ Tibial shaft fracture } & External fixation & Immediate weight bearing as tolerated $[14,15]$ \\
\hline & Intramedullary fixation & Immediate weight bearing as tolerated \\
\hline \multirow[t]{3}{*}{ Comminuted/high-grade tibial fracture } & ORIF & NWB for 6-12 weeks [16] \\
\hline & External fixation & Conflicted, likely support some duration of NWB $[12,17]$ \\
\hline & Intramedullary fixation & Immediate weight bearing as tolerated [18] \\
\hline \multirow[t]{2}{*}{ Distal femoral fracture } & ORIF & NWB for $6-12$ weeks \\
\hline & Intramedullary fixation & Immediate weight bearing as tolerated \\
\hline \multirow[t]{3}{*}{ Femoral shaft fracture } & ORIF & NWB for 6-12 weeks \\
\hline & External fixation & Immediate weight bearing as tolerated \\
\hline & Intramedullary fixation & Immediate weight bearing as tolerated \\
\hline \multirow[t]{2}{*}{ Comminuted femoral shaft fracture } & ORIF & NWB for 6-12 weeks \\
\hline & Intramedullary fixation & Immediate weight bearing as tolerated [19-22] \\
\hline \multirow[t]{2}{*}{ Hip fracture } & ORIF & NWB/restricted WB for 6-12 weeks \\
\hline & Percutaneous cancellous screw fixation & Immediate weight bearing as tolerated [23-25] \\
\hline \multirow[t]{4}{*}{ Vertically unstable pelvic fracture } & External fixation & NWB for $8-12$ weeks \\
\hline & ORIF & \\
\hline & Percutaneous fixation & \\
\hline & Hybrid & \\
\hline \multirow[t]{2}{*}{ Vertically stable pelvic fracture } & ORIF & NWB for $8-12$ weeks \\
\hline & External fixation & Immediate as tolerated $[26,27]$ \\
\hline
\end{tabular}

the setting of osteomyelitis, their application is particularly useful in the setting of trauma, when treating open fractures, especially with compromised soft tissue envelopes [30]. The protection of the interfragmentary space allows for the development of a callus but limits axial loading optimal for complete healing [31]. At times, limited healing with the use of external fixators and statically locked intramedullary devices must be overcome with dynamization. Dynamization allows for micromotion at the fracture site with weight bearing, further driving callus formation. This may be followed by a period of restricting the construct to minimize micromotion and stabilize the formed callus.

Multiple studies confirm the safety of immediate weight bearing after external fixation in most trauma settings, including calcaneal $[10,11]$, tibial plafond $[12,13]$, and tibial diaphysis [14, 15] fractures. However, some studies have demonstrated higher rates of nonunion and infection in AO type $\mathrm{C}$ and comminuted tibial diaphysis fractures [12, 17]. Among limb salvage patients undergoing long-term bone and soft tissue stabilization, particularly in the setting of distraction osteogenesis, ringed fixators with rigid constructs can be used to allow full weight bearing.

\section{Ligamentous Healing}

Depending on the location and extent of injury, ligamentous injuries can be treated in a multitude of fashions. Pelvic fractures in the trauma setting present particularly unique challenges, depending on the mechanism and severity of injury. Treatment options include limited weight bearing and no surgery, external fixation, ORIF, percutaneous fixation, or a hybrid of these fixation constructs. Critical to the success in treating these injuries is the ability to stabilize the pelvic ring, which predominantly relies on the healing of ligamentous as opposed to osseous structures. Ligamentous healing is characterized by the initial proliferative phase of healing, during which time weak and disorganized collagen is synthesized. The end of the proliferative phase of healing overlaps with remodeling, at which point the ligament is thought to have recovered sufficient strength. The period of non-weight bearing in ligamentous injury, as exemplified by pelvic instability, therefore reflects the $8-12$ weeks that ligaments require to recover strength before patients are able to tolerate normal weight bearing. While this remains the standard, some believe that rigid fixation replaces ligamentous support in vertically 
stable fractures and patients can be allowed to weight bear as tolerated $[26,27]$.

\section{Amputations}

Weight bearing following the closure of traumatic amputations is dependent upon the resolution of soft tissue wounds. Most importantly, a stable soft tissue envelope that will tolerate prosthetic wear requires full healing of all wounds and marked decrease in postoperative edema [32]. In our practice, we have found that this typically occurs within 4-6 weeks. This timeline cannot be dogmatic, however, because it is not uncommon for amputations of the lower extremity to also require additional soft tissue reconstructions, such as myocutaneous or free flap reconstruction with or without skin grafting, which may further delay prosthetic fitting. Traumatic lower extremity amputations are further often coincident with ipsilateral fractures or a destabilized pelvis, which will also prolong weight bearing. However, in the absence of ipsilateral fracture management or soft tissue concerns, weight bearing with a prosthesis can typically be initiated at 6 weeks' time, at which point both the deep myodeses and superficial incisions are adequately healed to prevent full weight bearing in a prosthetic trial socket, provided frequent skin checks are performed to assess soft tissue healing and integrity.

\section{Restricted Weight Bearing}

Given the benefits of early mobilization in returning to functional status, but taking into consideration the requirements for fracture and ligament healing, the use of progressive but restricted weight-bearing protocols would seem a viable compromise. For example, touchdown weight bearing, a common form of restricted weight bearing, is meant to reduce forces on joints during ambulation. One must consider that both nonweight bearing and touchdown weight bearing expend four times the energy for ambulation when compared to the average population [33]. Although patients often perceive touchdown weight bearing as being less tiring, both take an unnecessarily large physiological toll on patients attempting to recover. In addition, increasing evidence has called into question the rationale for these restrictive precautions. For example, multiple studies have shown that pressure on the acetabulum during non-restricted movements such as sit-to-stand far exceed the strains achieved during normal ambulation [34, 35].

In addition to these concerns, the most notable issue with restricted weight bearing is poor patient compliance. Patients consistently exceed the allowed "weight" in partial weight bearing, despite believing they are compliant $[33,36]$. Other methods of retraining such as the use of a scale, tactile hand under foot, verbal cues, and auditory biofeedback have also failed to demonstrate efficacy $[37,38]$. Furthermore, even the experience of the physical therapist does not seem to increase rates of compliance [39].

Because of the significant lack of compliance and unreliable teaching methods for partial weight bearing, methods have been developed to control forces on the lower extremities. These include body weight supports, hydrotherapy, and lower body positive pressure (LBPP) or "anti-gravity" treadmills. Patil et al. [40], using implanted instrumented knee prostheses, showed the use of the antigravity treadmill significantly decreased axial tibiofemoral forces and shear forces. While hydrotherapy may increase shear at joints at higher walking speeds, LBPP directly decreased anteroposterior shear across all speeds, with no significant changes in gait associated with change in LBPP-determined weight, unlike in other methods. These new modalities offer hope for the more reliable and controlled utilization of limited weight bearing in the rehabilitation of lower extremity trauma and, in our experience, have been very helpful in treating service members with combat-related trauma.

\section{Range of Motion}

The rehabilitation of orthopedic trauma in the lower extremity, particularly periarticular fractures of the knee and multiligamentous knee injuries (i.e., knee dislocations), is often complicated by joint stiffness. Joint stiffness associated with surgical repair of periarticular fractures may have long-term effects on mobility, gait, and function. Knee stiffness, which is a reduced range of motion (ROM) resulting in functional limitations, can impact normal leg swing and ability to ascend and descend stairs as well as rise from a seated position, particularly when entering or exiting a vehicle. Limited extension may result in a limp, quadriceps strain, functional leg-length shortening, and patellofemoral pain, thus compounding the resulting dysfunction.

Arthrofibrosis is typically a complication of a traumatic event, intra-articular or ligament surgery, arthroplasty, intraarticular fracture, or infection [41]. Arthrofibrosis can be potentiated by diabetes mellitus, lack of physical therapy, and immobilization [42]. Treatment for arthrofibrosis may include physical therapy with active-assisted and passive range of motion exercises, manipulation under anesthesia (MUA), arthroscopic or open lysis of adhesions, and/or quadricepsplasty $[43,44]$.

Manipulation has been applied for treatment of knee stiffness. However, MUA has not been well studied for posttraumatic stiffness and arthrofibrosis. Evans et al. [45] compared outcomes after operative treatment versus MUA in 56 patients with posttraumatic arthrofibrosis. Both groups received active-assisted and passive ROM exercises, regional anesthesia catheters, and continuous passive motion (CPM). Immediately and at 2-year follow-up, knees treated with MUA demonstrated significant improvement in the arc of motion 
with fewer complications over those treated with both open and arthroscopic lysis of adhesions. Unfortunately, and a notable limitation of that study, is that not all knees can be successfully manipulated by closed means without concurrent surgical intervention.

Since the treatments for arthrofibrosis are expensive, painful, and limited in their efficacy [46], prevention is preferred. Efird et al. [47] investigated the use of oral montelukast, intraarticular injections of forskolin, and intra-articular triamcinolone in rats for prophylaxis against post-traumatic arthrofibrosis. Results demonstrated efficacy of all treatments over untreated control in reducing stiffness by both reduced joint capsular contracture and reduced scar formation, with steroid injections being most efficacious. Similar results in humans would offer an additional tool for treating arthrofibrosis and optimizing function after injury. Regardless of novel preventative therapeutics, primary prevention via aggressive early motion is to be advocated as soon as osseous and soft tissue stability permits following injury.

\section{Continuous Passive Motion}

Continuous passive motion (CPM) is a form of early postoperative motion commonly used to reduce the development of stiffness after lower extremity injuries. However, the practical application of CPM is controversial due to the high monetary cost, extra work for nurses, and additional time of recumbency [48]. Several studies have investigated CPM's potential ability to facilitate faster recovery and better outcomes after articular fractures, with inconclusive findings. The use of CPM has been reported after the surgical fixation of articular femur fractures, both distal [49] and Hoffa type [50], and of acetabular fractures [51]. In a well-controlled trial, Boese et al. [52] demonstrated no significant differences in hospital stay, pain, or range of motion in 145 patients treated with CPM for 2 days post total knee arthroplasty (TKA), although CPM increased cost per patient by $\$ 2000$. It is clear that, while there is some evidence supporting the use of CPM after periarticular fractures, more studies will be needed to determine the ideal protocol for this therapy given the limited efficacy seen with TKA and the costs associated with this modality [53].

\section{Muscle Strengthening}

Diminished strength is very common following lower extremity injury. For patients with hip fracture, loss of strength contributes to rapid deterioration in function and an extremely high rate of repeat falls [54]. Multiple randomized controlled trials show that both community and home-based strengthtraining regimens moderately but significantly improve strength, balance, and functional mobility at 6 to 9 months following hip ORIF $[55,56]$. Additionally, strength training provides long-term reduction in patient's perceived difficulty completing activities of daily living (ADLs) compared to controls [57]. Strength training starting even as late as 6 months post-fixation can provide significant improvement of functional outcomes for an extended period of time even beyond the end of treatment [58].

The benefit achieved by muscle strengthening is not isolated to proximal femur fractures. In patients with acetabular fractures treated with ORIF, muscle strength was shown to be directly correlated with functional outcomes [59]. Strength training after the immobilization period for ankle fractures also results in significant functional improvement [60]. The benefit of strengthening exercises during the immobilization period, however, is less clear; however, a systematic review performed by Lin et al. [61] demonstrated that strength training contributes to significant improvements in activity, pain control, and range of motion, albeit at the risk of increased minor adverse events such as surgical wound irritation and arthrosis.

\section{Physiologic Value of Lower Extremity Rehabilitation}

As described above, evidence suggests the potential benefit to fracture healing and patient outcomes when early mobilization and muscle strengthening are employed during the rehabilitation of patients with lower extremity trauma. In addition, improved mobility also confers more general benefits, such as reduced risk of muscular atrophy, joint stiffness, venous thromboembolism (VTE) [40], and pressure ulcers [62]. In elderly patients recovering from hip fractures, the restoration of mobility is a critical goal as it allows improved independence with activities of daily living (ADLs), increases social interaction, and has even been shown to decrease mortality at 1-year follow-up [63]. Mobility also decreases permanent institutionalization in nursing homes, reducing financial burden on patients.

Orthopedic trauma has a relatively high incidence of deep vein thrombosis (DVT) and pulmonary embolism (PE) [64], with risk increased by injury severity score (ISS) $>50$, greater than two surgeries, a history of venous thromboembolism (VTE), comorbidities, traumatic brain injury, prolonged hospitalization, and reduced mobility [64-66]. In a cohort study of 18,151 orthopedic and trauma patients, Gudipati et al. [66] found that PE still developed in these patients despite mechanical and chemical thromboprophylaxis, implicating the importance of optimizing other modifiable risk factors. Even restricted weight bearing may be beneficial for VTE prevention, as venous return is not diminished in partial weight bearing when compared to full weight bearing [67].

\section{Pain Management}

Intense postoperative pain is a major risk factor for transition to chronic pain [68]. In addition, inadequate pain control is 
often associated with longer bedrest, delays in ambulation and physical therapy, increased rate of VTE, and poor functional outcomes [68]. Pain, particularly chronic pain, is complex and very challenging to treat. The effective management of complex pain often requires a multimodal approach including a shift away from pharmacologics and opiates, with emphasis toward rehabilitation, cognitive techniques, and managing psychologic aspects of pain. Because of the complexities in managing pain and its significant impact on orthopedic trauma outcome, a further review of some of the advances in pain management is discussed below.

\section{Acute/Postoperative Pain}

Orthopedic trauma and surgical pain are often severe and prolonged. Many methods have been used to control this pain, with multimodal approaches showing improved analgesia, better patient satisfaction, and decreased opiate use postoperatively in multiple studies [69]. Peripheral nerve blocks (PNB), particularly after lower extremity surgery [70, 71], are reported to have fewer side effects than IV opioids [72] and epidurals [73]. Aguirre et al. [74] supported the use of continuous peripheral nerve block (cPNB) postoperatively for its adequate pain control without need for large bolus doses as with single-injection blocks, thus reducing the risk of systemic toxicity, positioning injury, and falls [75]. Blumenthal et al. [76] found that cPNB for $48 \mathrm{~h}$ after major ankle surgery resulted in decreased pain at 6-month follow-up. This may be due to better mobilization and rehabilitation or directly due to inhibiting pain "chronification."

Many low-risk non-pharmacologic approaches normally applied for chronic pain control may also be useful for postoperative pain, including acupuncture, thermal therapy, massage, and cognitive techniques such as relaxation, guided imagery, and music therapy [77]. One approach that has been studied with good result is transcutaneous electrical nerve stimulation (TENS), which has been shown to reduce postoperative opioid use in multiple controlled studies [78].

\section{Chronic Pain}

Chronic pain is extremely common after limb-threatening lower extremity injury [79]. Many studies have focused on the prevention of chronic pain, with the major focus being multimodal analgesia as defined above [80]. Pharmacologics including opioids, NSAIDs, local and regional anesthetics, anticonvulsants, antidepressants, and NMDA antagonists have shown some degree of benefit in preventing chronic pain. Several non-pharmacologic methods have been studied for control of this pain with proven benefit including cognitive behavioral therapy (CBT) [81] and repetitive transcranial magnetic stimulation (rTMS) [82]. Unfortunately, CBT has been notoriously difficult to study due to non-uniform application and lack of meaningful outcome measures [81]; however, in a recent study, Nash et al. [83] demonstrated increased pain self-efficacy in patients with chronic pain after CBT.

\section{Complex Regional Pain Syndrome}

One troublesome complication of chronic post-traumatic pain is the development of complex regional pain syndrome (CRPS). CRPS is a clinical process starting hours to days after initial injury that involves severe, chronic pain with hypersensitivity to normal stimuli. The pain is also typified by autonomic skin changes with cyanosis, altered temperature, and inappropriate sweat response, and increasing joint stiffness accompanied by muscle wasting and bone demineralization [84]. Several studies suggest that vitamin C may help prevent the development of CRPS, particularly after foot/ankle surgery [85]. Treatment is difficult, especially in lower extremities [86], and many modalities lack sufficient evidence to guide therapy.

Opiates, by definition in cases of CRPS, provide insubstantial pain relief or return to function and increase dependence. Anticonvulsants have shown some efficacy in pain reduction in these patients [87], whereas NSAIDs result in very shortterm benefit of about 15 days [88]. In a review of 76 RCTs, Albazaz et al. [89] showed sympathetic blockade to be viable diagnostically and therapeutically short term for a subset of patients whose pain is likely sympathetically mediated; however, evidence does not support long-term efficacy [90]. In a review of $16 \mathrm{RCTs}$, Wertil et al. [91] determined that bisphosphonates are effective at long-term pain control in early CRPS and therefore may offer an alternative approach to treatment.

The use of non-pharmacologics is also widely studied for the treatment of CRPS. Grabow et al. [92] found that spinal cord stimulation (SCS) may be successful in 60-91\% of patients with CRPS. In a long-term follow-up study, Kemler et al. [93] showed that SCS with physical therapy resulted in significantly decreased pain but with no change in functional status, at 6 and 24 months. Pulsed radiofrequency (PRF) of the DRG has also increased for chronic pain syndromes, though there is insufficient evidence to indicate its utility in CRPS.

Civilian and Military Outcomes Following Lower Extremity Trauma

Rehabilitation after lower extremity trauma is extremely difficult and has been studied largely comparing lower extremity amputation and limb salvage. The Lower Extremity Assessment Project (LEAP), a multicenter study of lower extremity trauma in US civilians, assessed 2- and 7-year outcomes of patients treated with limb salvage or amputation. In these patients, critical factors in the decision to amputate were severe 
Fig. 1 (top left) A clinical photograph of a US Marine who sustained severe bilateral open tib/fib and bilateral comminuted calcaneal fractures in 2011 (radiographs of left and right shown at bottom). On the right are follow-up radiographs of this patient, who now ambulates with bilateral Intrepid Dynamic Exoskeletal Orthosis (IDEO) (shown at top right) and is now in the Return to Run program

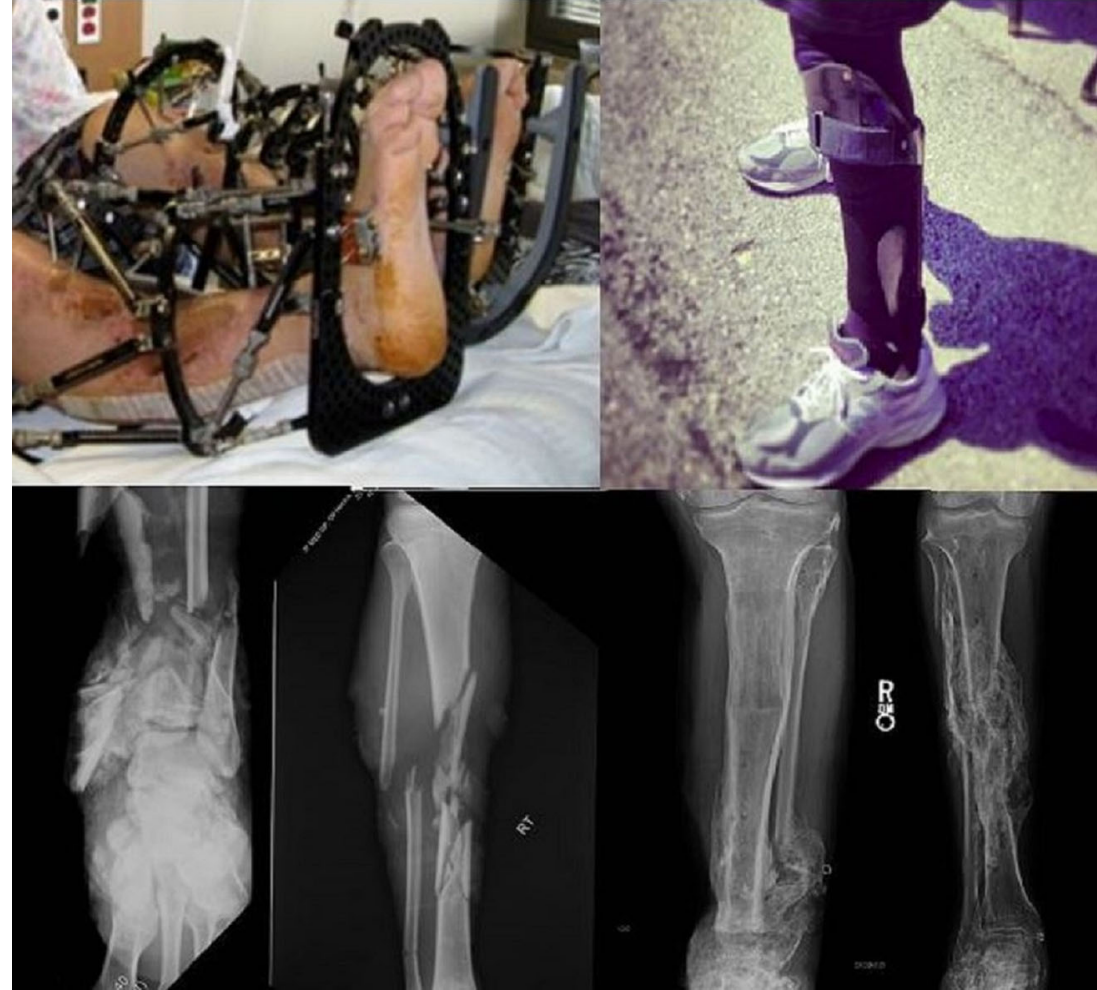

muscle injury, absence of plantar sensation, open foot fracture, vascular injury, bone loss, and tibial fracture pattern [94]. The LEAP study found high levels of disability in half of patients, with no difference in functional outcomes between amputation and limb salvage [95-97]. Only patients with throughknee-amputations (TKAs) had worse outcomes [98] in LEAP, although this finding has recently been countered by PennBarnwell et al. [99] whose systematic review showed improved function of TKAs compared to transfemoral amputations, despite increased pain with prosthetic wear.

Perhaps paramount in the LEAP study were the findings that socioeconomic factors, rather than surgeon-controlled variables or injury factors, were most related to functional outcomes and quality of life [100]. The early predictors of chronic pain included lower education level, low self-efficacy, and high baseline alcohol consumption, while 3-month postdischarge predictors included high pain intensity, sleep dysfunction, and increased depression and anxiety [79]. Financially, long-term outcomes of prosthesis bear a higher cost over a lifetime, projected as $\$ 509,275$ compared to $\$ 163,282$ in limb salvage patients [101].

The outcomes of the LEAP study provide a powerful tool in understanding factors involved in recovery from lower extremity trauma; however, these findings may not be generalizable to all populations. Compared to civilian populations, military trauma patients are typically younger, in better physical condition, and have access to aggressive rehabilitation and prosthesis services. The Military Extremity Traumatic
Amputation/Limb Salvage (METALS) study [102••] evaluated 239 patients after unilateral or bilateral lower extremity trauma treated with limb salvage or amputation. Overall, patients reported moderate-to-high levels of physical and psychosocial disability. Older age was also associated with increased pain interference and reduced functional status. Meanwhile, strong social support resulted in better physical and psychosocial functioning.

The results of the METALS study indicated that at 37.5month follow-up, patients with single limb amputations reported significantly better functional outcomes compared to limb salvage, with no significant effect of amputation level. Interestingly, there was also no significant trend toward better outcomes in bilateral amputations compared to single limb salvage. Individuals with amputation were 2.6 times as likely to engage in vigorous activity, although no differences were seen in depression rates or pain interference. The improved outcomes in military service members with amputation has been attributed to their higher rates of early, focused rehabilitation as compared to those in the military limb salvage group or civilian cohorts [102••]. Furthermore, as described, military service members with lower limb amputation were able to transition more rapidly to weight bearing, whereas full weight bearing generally occurs after more than 3 months in most patients undergoing limb salvage.

Psychological injury is also of considerable concern for individuals with lower extremity trauma. Within the METALS study, $38.3 \%$ of patients reported symptoms of depression, 
with $13 \%$ meeting criteria for major depression, and $17.9 \%$ with PTSD. These results are commensurate with those reported in the LEAP study, reflecting the high rates of psychologic disease seen in these patient populations. A recent study by Vranceanu et al. [103] showed that catastrophic thinking/ pain catastrophizing was the most significant predictor of pain and disability at 5-8 months follow-up after musculoskeletal trauma. This study supports the use of cognitive behavioral therapy (CBT) as an adjunct for patients with greater pain or disability than expected, as addressing PTSD and pain catastrophization early may improve outcomes, along with reducing medical costs.

\section{Advances in Lower Extremity Trauma Rehabilitation: Lessons From Current Conflict}

As an adjunct to the early and focused amputee rehabilitation at military treatment facilities (MTFs), the US Department of Defense created multiple Amputee Centers of Excellence to conduct research to improve rehabilitation of wounded soldiers and provide a multidisciplinary approach to care and rehabilitation [104•], including the formation of a DoD and Department of Veterans Affairs Center of Excellence for Extremity Trauma and Amputee Center of Excellence (EACE). In addition, several research consortiums have been formed through coordinated efforts by multiple federal and nonfederal agencies. Research from these centers has resulted in the formation of improved clinical practice guidelines, enhanced methods for assessing and optimizing gait and mobility, advanced lower limb orthotics and prosthetics, as well as more aggressive rehabilitation protocols to help return individuals with lower extremity limb loss and dysfunction to their highest level of function [104•].

These technology advances have enhanced functional outcomes immensely in service members with amputation, but until recently, there were few similar advances in patients undergoing limb salvage. Patzkowski et al. [105] attributes the high functional loss in limb salvage patients to muscle loss, nerve injury, and pain, and indicated the need for development of better orthoses given the high rate of delayed elective amputations. In a study of these patients using the Intrepid Dynamic Exoskeletal Orthosis (IDEO) brace (shown in Fig. 1), a relatively new energy-storing carbon fiber orthosis, they demonstrated significant improvements in functional performance compared to all other brace types in virtually all parameters. Hsu et al. [106] showed a similar improvement with IDEO brace in nearly all physical performance measures, thereby leading patients originally desiring amputation to settle on limb salvage.

The IDEO brace has subsequently become an integral component of the Return to Run program, which is combined with high-intensity physical therapy to restore function in limb salvage patients, and has demonstrated success in assisting patients to regain high-level functioning [107]. In a recent study of 84 limb salvage patients enrolled in the Return to Run program for 8 weeks, Bedigrew et al. [108] demonstrated significant improvement in physical performance measures and an $82 \%$ reduction in ire for delayed amputation.

\section{Conclusion}

The process of rehabilitation after lower extremity and pelvic fractures involves a complex interplay of goals that ideally result in a stable, functional, and pain-free bone, joint, and lower extremity. Extensive research from past years has provided a framework of understanding how these goals may be achieved, although many limitations in our knowledge still exist. Future research will ideally focus on the further refinement of surgical fixators and their application to optimize early loading without complication, improved prevention and treatment of contracture formation and stiffness after periarticular insult, post-traumatic pain extinction, and continued development of orthoses and prostheses with nearbiologic functionality. In the meantime, controlled but appropriately aggressive early mobilization and range of motion with progressive weight bearing, combined with multimodal pain control and psychosocial support, is indicated for all patients with limb-threatening lower extremity trauma and/or amputation.

Acknowledgments All of the authors are employees of the US Government, and this work was prepared as part of their official duties. As such, there is no copyright to transfer. The views expressed in this article are those of the authors and do not necessarily reflect the official policy or position of the Department of the Navy, Department of the Army, Department of Defense, nor the US Government. We certify that all individuals who qualify as authors have been listed; each has participated in the conception and design of this work, the analysis of data, the writing of the document, and the approval of the submission of this version; that the document represents valid work; that if we used information derived from another source, we obtained all necessary approvals to use it and made appropriate acknowledgements in the document; and that each takes public responsibility for it. Nothing in the presentation implies any Federal/ DOD/DON endorsement. None of the authors received financial support for this study.

\section{Compliance with Ethics Guidelines}

Conflict of Interest Benjamin W. Hoyt, Gabriel J. Pavey, Paul F. Pasquina, and Benjamin K. Potter declare that they have no conflict of interest.

Each author certifies that he or she has no commercial associations (e.g., consultancies, stock ownership, equity interest, patent/licensing arrangements, etc.) that might pose a conflict of interest in connection with the submitted article.

Human and Animal Rights and Informed Consent This article does not contain any studies with human or animal subjects performed by any of the authors. 


\section{References}

Papers of particular interest, published recently, have been highlighted as:

- Of importance

- Of major importance

1. Wolff J. The law of bone remodeling. Verlag: Springer; 1986.

2. Martin RB, Burr DB, Sharkey NA. Skeletal tissue mechanics. New York: Springer; 1998.

3. Klein P, Schell H, Streitparth F, Heller M, Kassi JP, Kandziora F, et al. The initial phase of fracture healing is specifically sensitive to mechanical conditions. J Orthop Res. 2003;21(4):662-9.

4. Zhao F, Zhou Z, Yan Y, Yuan Z, Yang G, Yu H, et al. Effect of fixation on neovascularization during bone healing. Med Eng Phys. 2014;36(11):1436-42.

5. Perren SM. Evolution of the internal fixation of long bone fractures: the scientific basis of biological internal fixation: choosing a new balance between stability and biology. J Bone Joint Surg (Br). 2002;84(B):1093-110.

6. Perren SM. Physical and biological aspects of fracture healing with special reference to internal fixation. Clin Orthop. 1979;138:175-96.

7. Haller JM, Potter MQ, Kubiak EN. Weight bearing after a periarticular fracture. Orthop Clin N Am. 2013;44(4):509-19. Article focuses on significant advances in periarticular lower extremity trauma and weight bearing protocols to optimize recovery. Some concepts introduced within this article are novel approaches to rehabilitation protocols, and highlight a growing trend towards earlier weight bearing following fixation.

8. Hyer CF, Atway S, Berlet GC, Lee TH. Early weight bearing of calcaneal fractures fixated with locked plates: a radiographic review. Foot Ankle Spec. 2010;3(6):320-3.

9. Buckley R, Tough S, McCormack R, Pate G, Leighton R, Petrie $\mathrm{D}$, et al. Operative compared with nonoperative treatment of displaced intra-articular calcaneal fractures: a prospective, randomized, controlled multicenter trial. J Bone Joint Surg Am. 2002;84(10):1733-44.

10. Paley D, Fischgrund J. Open reduction and circular external fixation of intraarticular calcaneal fractures. Clin Orthop Relat Res. 1993;290:125-31.

11. Talarico LM, Vito GR, Zyryanov SY. Management of displaced intraarticular calcaneal fractures by using external ring fixation, minimally invasive open reduction, and early weightbearing. J Foot Ankle Surg. 2004;43(1):43-50.

12. Bacon S, Smith WR, Morgan SJ, Hasenboehler E, Phillips G, Williams A, et al. A retrospective analysis of comminuted intraarticular fractures of the tibial plafond: open reduction and internal fixation versus external Ilizarov fixation. Injury. 2008;39(2):196202.

13. Zarek S, Othman M, Macias J. The Ilizarov method in the treatment of pilon fractures. Ortop Traumatol Rehabil. 2002;4(4):42733.

14. Joslin CC, Eastaugh-Waring SJ, Hardy JRW, Cunningham JI. Weight bearing after tibial fracture as a guide to healing. Clin Biomech. 2008;23(3):329-33.

15. Kershaw CJ, Cunningham JL, Kenwright J. Tibial external fixation, weight bearing, and fracture movement. Clin Orthop Relat Res. 1993;293:28-36.

16. Segal D, Mallik AR, Wetzler MJ, Franchi AV, Whitelaw GP. Early weight bearing of lateral tibial plateau fractures. Clin Orthop Relat Res. 1993;294:232-7.
17. Mitkovic MB, Bumbasirevic MZ, Lesic A, Golubovic Z. Dynamic external fixation of comminuted intraarticular fractures of the distal tibia (type C pilon fractures). Acta Orthop Belg. 2002;68(5):508-14.

18. Leahy M. 2014. Is immediate weight bearing safe for tibial shaft fractures treated with IM nails? AAOS Now. 8(10).

19. Arazi M, Ogun TC, Oktar MN, Memik R, Kutlu A. Early weightbearing after statically locked reamed intramedullary nailing of comminuted femoral fractures: is it a safe procedure? J Trauma. 2001;50(4):711-6.

20. Brumback RJ, Toal Jr TR, Murphy-Zane MS, Novak VP, Belkoff SM. Immediate weight-bearing after treatment of a comminuted fracture of the femoral shaft with a statically locked intramedullary nail. J Bone Joint Surg Am. 1999;81(11):1538-44.

21. Herrera A, Domingo J, Martinez A. Results of osteosynthesis with the ITST nail in fractures of the trochanteric region of the femur. Int Orthop. 2008;32(6):767-72.

22. Lin SJ, Chen CL, Peng KT, Hsu WH. Effect of fragmentary displacement and morphology in the treatment of comminuted femoral shaft fractures with an intramedullary nail. Injury. 2014;45(4): $752-6$.

23. Kazemi N, Archdeacon MT. Immediate full weightbearing after percutaneous fixation of anterior column acetabulum fractures. J Orthop Trauma. 2012;26(2):73-9.

24. Conn KS, Parker MJ. Undisplaced intracapsular hip fractures: results of internal fixation in 375 patients. J Orthop Trauma. 2004:421:249-54.

25. Koval KJ, Sala DA, Kummer FJ, Zuckerman JD. Postoperative weightbearing after a fracture of the femoral neck or an intertrochanteric fracture. J Bone Joint Surg Am. 1998;80(3): 352-6.

26. Cole JD, Blum DA, Ansel LJ. Outcome after fixation of unstable posterior pelvic ring injuries. Clin Orthop Relat Res. 1996;329: $160-79$.

27. Tornetta P, Dickson K, Matta JM. Outcome of rotationally unstable pelvic ring injuries treated operatively. Clin Orthop Relat Res. 1996;329:147-51.

28. Bailón-Plaza A, van der Meulen MCH. Beneficial effects of moderate, early loading and adverse effects of delayed or excessive loading on bone healing. J Biomech. 2003;36(8): 1069-77.

29. Zlowodzki M, Vogt D, Cole PA, Kregor PJ. Plating of femoral shaft fractures: open reduction and internal fixation versus submuscular fixation. J Trauma. 2007;63(5):1061-5.

30. Claes L, Heitemeyer U, Krischak G, Braun H, Hierholzer G. Fixation technique influences osteogenesis of comminuted fractures. Clin Orthop. 1999;365:221-9.

31. Ilizarov GA. 1992. The apparatus: components and biomechanical principles of application. Green S (Ed) Transosseus osteosynthesis. Theoretical and clinical aspects of the regeneration and growth of tissue. Berlin: Springer-Verlag. 63-136.

32. Tintle SM, Keeling JJ, Shawen SB, Forsberg JA, Potter BK. Traumatic and trauma-related amputation: part I: general principles and lower-extremity amputations. J Bone Joint Surg Am. 2010;92-A(17):2852-68.

33. Hurkmans HL, Bussmann JB, Selles RW, Benda E, Stam HJ, Verhaar JA. The difference between actual and prescribed weight bearing of total hip patients with a trochanteric osteotomy: long-term vertical force measurements inside and outside the hospital. Arch Phys Med Rehabil. 2007;88(2):2006.

34. Yoshida H, Faust A, Wilckens J, Kitagawa M, Fetto J, Chao EYS. Three-dimensional dynamic hip contact area and pressure distribution during activities of daily living. J Biomech. 2006;39(11): 1996-2004. 
35. Bergmann G, Deuretzbacher G, Heller M, Graichen F, Rohlmann A, Strauss J, et al. Hip contact forces and gait patterns from routine activities. J Biomech. 2001;34(7):859-71.

36. Hustedt JW, Blizzard DJ, Baumgaertner MR, Leslie MP, Grauer $\mathrm{JN}$. Is it possible to train patients to limit weight bearing on a lower extremity? Orthopedics. 2012;35(1):e31-7.

37. Chow DH, Cheng CT. Quantitative analysis of the effects of audio biofeedback on weight-bearing characteristics of persons with transtibial amputation during early prosthetic ambulation. J Rehabil Res Dev. 2000;37:255-60.

38. Malviya A, Richards J, Jones RK, Udwadia A, Doyle J. Reproducibility of partial weight bearing. Injury. 2005;36(4): 556-9.

39. Ruiz FK, Fu MC, Bohl DD, Hustedt JW, Baumgaertner MR, Leslie MP, et al. Patient compliance with postoperative lower extremity touch-down weight-bearing orders at a level I academic trauma center. Orthopedics. 2014;37(6):e552-6.

40. Patil S, Steklov N, Bugbee WD, Goldberg T, Colwell CW, D'lima DD. Anti-gravity treadmills are effective in reducing knee forces. J Orthop Res. 2013;31(5):672-9.

41. Vander Have KL, Ganley TJ, Kocher MS, et al. Arthrofibrosis after surgical fixation of tibial eminence fractures in children and adolescents. Am J Sports Med. 2010;38(2):298-301.

42. Tighe CB, Oakley Jr WS. The prevalence of a diabetic condition and adhesive capsulitis of the shoulder. South Med J. 2008;101: 591-5.

43. Fitzsimmons SE, Vazquez EA, Bronson MJ. How to treat the stiff total knee arthroplasty? A systematic review. Clin Orthop Relat Res. 2010;468(4):1096-106.

44. Daoud H, O'Farrell T, Cruess RL. Quadricepsplasty. The Judet technique and results of six cases. J Bone Joint Surg (Br). 1982;64(2):194-7.

45. Evans KN, Lewandowski L, Pickett A, Strauss JE, Gordon WT. Outcomes of manipulation under anesthesia versus surgical management of combat-related arthrofibrosis of the knee. J Surg Orthop Adv. 2014;22(1):36-41.

46. Su EP. Fixed flexion deformity and total knee arthroplasty. Bone Joint Surg Br. 2012;94(B):112-5.

47. Efird W, Kellam P, Yeazell S, Weinhold P, and Dahners LE. 2014. An evaluation of prophylactic treatments to prevent post traumatic joint stiffness. J Orthop Res. 1520-4.

48. Beaupre' LA, Davies DM, Jones CA, Cinats JG. Exercise combined with continuous passive motion or slider board therapy compared with exercise only: a randomized controlled trial of patients following total knee arthroplasty. Phys Ther. 2001;81(4): 1029-37.

49. Ostermann PA, Neumann K, Ekkernkamp A, Muhr G. Long term results of unicondylar fractures of the femur. J Orthop Trauma. 1994;8(2):142-6.

50. Papadopoulos AX, Panagopoulos A, Karageorgos A, Tyllianakis M. Operative treatment of unilateral bicondylar Hoffa fractures. J Orthop Trauma. 2004;18(2):119-22.

51. Brumback RJ, Holt ES, McBride MS, Poka A, Bathon GH, Burgess AR. Acetabular depression fracture accompanying posterior fracture dislocation of the hip. J Orthop Trauma. 1990;4(1): 42-8.

52. Boese CK, Weis M, Phillips T, Lawto-Peters S, Gallo T, Centeno L. The efficacy of continuous passive motion after total knee arthroplasty: a comparison of three protocols. J Arthroplasty. 2014;29(6):1158-62.

53. Onderko LL, Rehman S. Treatment of articular fractures with continuous passive motion. Orthop Clin N Am. 2013;44:345-56.

54. Binder EF, Brown M, Sinacore DR, Steger-May K, Yarasheski $\mathrm{KE}$, Schechtman KB. Effects of extended outpatient rehabilitation after hip fracture: a randomized controlled trial. JAMA. 2004;292(7):837-46.
55. Auais MA, Eilayyan O, Mayo NE. Extended exercise rehabilitation after hip fracture improves patients' physical function: a systematic review and meta-analysis. Phys Ther. 2012;92(11):143751.

56. Latham NK, Harris BA, Bean JF, Heeren T, Goodyear C, Zawacki $\mathrm{S}$, et al. Effect of a home-based exercise program on functional recovery following rehabilitation after hip fracture. JAMA. 2014;311(7):700-8.

57. Edgren J, Rantanen T, Heinonen A, Portegijs E, Alén M, Kiviranta I, et al. Effects of progressive resistance training on physical disability among older community-dwelling people with history of hip fracture. Aging Clin Exp Res. 2012;24(2):171-5.

58. Mangione KK, Craik RL, Palombaro KM, Tomlinson SS, Hofmann MT. Home-based leg-strengthening exercise improves function 1 year after hip fracture: a randomized controlled study. J Am Geriatr Soc. 2010;58(10):1911-7.

59. Borrelli J, Ricci WM, Anglen JO, Gregush R, Engsberg J. Muscle strength recovery and its effects on outcome after open reduction and internal fixation of acetabular fractures. J Orthop Trauma. 2006;20(6):388-95.

60. Shaffer MA, Okereke E, Esterhai Jr JL, Elliott MA, Walker GA, Yim SH, et al. Effects of immobilization on plantar-flexion torque, fatigue resistance, and functional ability following an ankle fracture. Phys Ther. 2000;80(8):769-80.

61. Lin CW, Donkers NA, Refshauge KM, Beckenkamp PR, Khera $\mathrm{K}$, Moseley AM. Rehabilitation for ankle fractures in adults. Cochrane Database Syst Rev. 2012;11, CD005595.

62. Lindgren M, Unosson M, Fredrikson M, Ek A. Immobility-a major risk factor for development of pressure ulcers among adult hospitalized patients: a prospective study. Scand J Caring Sci. 2004;18(1):57-64

63. Egol KA, Koval KJ, Zuckerman JD. Functional recovery following hip fracture in the elderly. J Orthop Trauma. 1997;11(8):594 9.

64. Paffrath T, Wafaisade A, Lefering R, Simanski C, Bouillon B, Spanholtz T, et al. Trauma registry of DGU: venous thromboembolism after severe trauma: incidence, risk factors and outcome. Injury. 2010;41:97-101.

65. Reiff DA, Haricharan RN, Bullington NM, Griffin RL, McGwin Jr G, Rue III LW. Traumatic brain injury is associated with the development of deep vein thrombosis independent of pharmacological prophylaxis. J Trauma. 2009;66:1436-40.

66. Gudipati S, Fragkakis EM, Ciriello V, Harrison SJ, Stavrou PZ, Kanakaris NK, et al. A cohort study on the incidence and outcome of pulmonary embolism in trauma and orthopedic patients. BMC Med. 2014;12(39):e1-11.

67. Eisele R, Weickert E, Eren A, Kinzl L. The effect of partial and full weight-bearing on venous return in the lower limb. J Bone Joint Surg-Brit. 2001;83B(7):1037-40.

68. Kehlet H, Jensen TS, Woolf CJ. Persistent postsurgical pain: risk factors and prevention. Lancet. 2006;367(9522):1618-25.

69. Kang H, Ha YC, Kim JY, Woo YC, Lee JS, Jang EC. Effectiveness of multimodal pain management after bipolar hemiarthroplasty for hip fracture. J Bone Joint Surg Am. 2013;95:291-6.

70. Singelyn FJ, Ferrant T, Malisse MF, Joris D. Effects of intravenous patient-controlled analgesia with morphine, continuous epidural analgesia, and continuous femoral nerve sheath block on rehabilitation after unilateral total-hip arthroplasty. Reg Anesth Pain Med. 2005;30(5):452-7.

71. Sirianni E. Postoperative pain management following total knee arthroplasty: a randomized comparison of continuous epidural versus femoral nerve infusion. J Knee Surg. 2006;19(2):137-43.

72. Malinzak EB, Gan TJ. Regional anesthesia for vascular access surgery. Anesth Analg. 2009;109(3):976-80. 
73. Capdevila X, Barthelet Y, Biboulet P, Ryckwaert Y, Rubenovitch J, D'Athis F. Effects of perioperative analgesic technique on the surgical outcome and duration of rehabilitation after major knee surgery. Anesthesiology. 1999;91(1):8-15.

74. AguirreJ, Del Moral A, Cobo I, Borgeat A, and Blumenthal S. 2012. The role of continuous peripheral nerve blocks. Anesthesiol Res Pract. 2012: 560879.

75. Ilfeld BM, Duke KB, Donohue MC. The association between lower extremity continuous peripheral nerve blocks and patient falls after knee and hip arthroplasty. Anesth Analg. 2010;111(6): $1552-4$.

76. Blumenthal S, Borgeat A, Neudrfer C, Bertolini R, Espinosa N, Aguirre J. Additional femoral catheter in combination with popliteal catheter for analgesia after major ankle surgery. Brit $\mathrm{J}$ Anaesth. 2011;106(3):387-93.

77. Salama-Hanna J, Chen G. Patients with chronic pain. Med Clin N Am. 2013;97:1201-15.

78. Bjordal JM, Johnson MI, Ljunggreen AE. Transcutaneous electrical nerve stimulation (TENS) can reduce postoperative analgesic consumption. A meta-analysis with assessment of optimal treatment parameters for postoperative pain. Eur J Pain. 2003;7(2): $181-8$.

79. Castillo RC, MacKenzie EJ, Wegener ST, Bosse MJ, The LEAP Study Group. Prevalence of chronic pain seven years following limb threatening lower extremity trauma. Pain. 2006;124:321-9.

80. McGreevy K, Bottros MM, Raja SN. Preventing chronic pain following acute pain: risk factors, preventive strategies, and their efficacy. Eur J Pain Suppl. 2011;5(2):365-72.

81. Morley S. Efficacy and effectiveness of cognitive behaviour therapy for chronic pain: progress and some challenges. Pain. 2011;152:s99-106.

82. Young NA, Shama M, Deogaonkar. Transcranial magnetic stimulation for chronic pain. Neurosurg Clin N Am. 2014;25:819-32.

83. Nash VR, Ponto J, Toensend C, Nelson P, Bretz MN. Cognitive behavioral therapy, self-efficacy, and depression in persons with chronic pain. Pain Manag Nurs. 2013;14(4):e236-43.

84. Hogan CJ, Hurwitz SR. Treatment of complex regional pain syndrome of the lower extremity. J Am Acad Orthop Surg. 2002;10: 281-9.

85. Besse JL, Gadeyne S, Galand-Desme S, Lerat J, Moyen B. Effect of vitamin $\mathrm{C}$ on prevention of complex regional pain syndrome type I in foot and ankle surgery. Foot Ankle Surg. 2009;15(4): $179-82$

86. Poplawski ZJ, Wiley AM, Murray JF. Post-traumatic dystrophy of the extremities. J Bone Joint Surg Am. 1983;65:642-55.

87. Mellick GA, Mellick LB. Reflex sympathetic dystrophy treated with gabapentin. Arch Phys Med Rehabil. 1997;78:98-105.

88. Vanos DN, Ramamurthy S, Hoffman J. Intravenous regional block using ketorolac: preliminary results in the treatment of reflex sympathetic dystrophy. Anesth Analg. 1992;74:139-41.

89. Albazaz R, Wong YT, Homer-Vanniasinkam S. Complex regional pain syndrome: a review. Ann Vasc Surg. 2008;22:297-306.

90. Cepeda MS, Lau J, Carr DB. Defining the therapeutic role of local anesthetic sympathetic blockade in complex regional pain syndrome: a narrative and systematic review. Clin J Pain. 2002;18: 216-33.

91. Wertil MM, Kessels AGH, Perez RSGM, Bachmann LM, Brunner F. Rational pain management in complex regional pain syndrome 1 (CRPS 1) - a network meta-analysis. Pain Med. 2014;15:157589.

92. Grabow TS, Tella PK, Raja SN. Spinal cord stimulation for complex regional pain syndrome: an evidence-based medicine review of the literature. Clin J Pain. 2003;19:371-83.
93. Kemler MA, de Vet HC, Barendse GA, van den Wildenberg FA, van Kleef M. Effect of spinal cord stimulation for chronic complex regional pain syndrome type I: five-year final follow-up of patients in a randomized controlled trial. J Neurosurg. 2008;108(2):292-8.

94. Swiontkowski MF, Ellen JM, Bosse MJ, Jones AL, Travison T. Factors influencing the decision to amputate or reconstruct after high-energy lower extremity trauma. J Trauma. 2002;52(4):6419.

95. Bosse MJ, MacKenzie EJ, Kellam JF, Burgess AR, Webb LX, Swiontkowski MF, et al. An analysis of outcomes of reconstruction or amputation after leg threatening injuries. N Engl J Med. 2002;347(24):1924-31.

96. MacKenzie EJ, Bosse MJ, Pollak AN, Webb LX, Swiontkowski MF, Kellam JF, et al. Long-term persistence of disability following severe lower-limb trauma. Results of a seven-year follow-up. J Bone Joint Surg Am. 2005;87(8):1801-9.

97. McCarthy ML, MacKenzie EJ, Edwin D, Bosse MJ, Castillo RC, Starr A, et al. Psychological distress associated with severe lowerlimb injury. J Bone Joint Surg Am. 2003;85(9):1689-97.

98. Mackenzie EJ, Bosse MJ, Castillo RC, et al. Functional outcomes following trauma-related lower extremity amputation. J Bone Joint Surg Am. 2004;86(8):1636-45.

99. Penn-Barnwell JG. Outcomes in lower limb amputation following trauma: a systematic review and meta-analysis. Injury. 2011;42: 1474-9.

100. Higgins TF, Klatt BK, Beals TC. Lower extremity assessment project (LEAP) - the best available evidence on limb-threatening lower extremity trauma. Orthop Clin N Am. 2010;41:233-9.

101. Mackenzie EJ, Castillo RC, Jones AS, et al. Healthcare costs associated with amputation or reconstruction of a limb-threatening injury. J Bone Joint Surg Am. 2007;89(8):1685-92.

102.• Doukas WC, Hayda RA, Frisch HM, Andersen RC, Mazurek MT, Ficke JR, et al. The military extremity trauma amputation/limb salvage (METALS) study: outcomes of amputation versus limb salvage following major lower-extremity trauma. J Bone Joint Surg Am. 2013;95(2):138-45. The METALS study provides a long-term assessment of functional outcomes after military lower extremity trauma. This work supplements previous findings of the LEAP study, but highlights the value of an enriched psychosocial environment experienced within military populations that may improve outcomes in military lower extremity trauma patients.

103. Vranceanu A, Bachoura A, Weening A, Vrahas M, Smith RM, Ring D. Psychological factors predict disability and pain intensity after skeletal trauma. J Bone Joint Surg Am. 2014;96(e20):1-6.

104. Gordon WT, Stannard JP, Pasquina JP, Archer KR, Extremity War Injuries VII Rehabilitation Panel. Evolution of orthopaedic rehabilitation care. J Am Acad Orthop Surg. 2012;20(S1):S80-3. Article provides a review of recent advances in research centers and technology for functional recovery after military lower extremity trauma. These novel approaches may offer a model for civilian trauma centers in rehabilitation of similar patients.

105. Patzkowski JC, Blanck RV, Owens JG, Wilken JM, Kirk KL, Wenke JC, et al. Comparative effect of orthosis design on functional performance. J Bone Joint Surg Am. 2012;94:507-15.

106. Hsu J, Bosse MJ. Challenges in severe lower limb injury rehabilitation. JAAOS. 2012;20(S1):S39-41.

107. Owens JG, Blair JA, Patzkowski JC, Blanck RV, Hsu JR. Skeletal trauma research consortium: return to running and sports participation after limb salvage. J Trauma. 2011;71(1S):S120-4.

108. Bedigrew KM, Patzkowski JC, Wilken JM, Owens JG, Blanck RV, Stinner DJ, et al. Can an integrated orthotic and rehabilitation program decrease pain and improve function after lower extremity trauma? Clin Orthop Relat Res. 2014;472:3017-25. 